\title{
Situación del Zika en Colombia: experiencia de miembros de la Red Colombiana de Colaboración en Zika (RECOLZIKA)
}

\section{The Zika virus situation in Colombia: the experience of members from the Colombian collaborative network for Zika (RECOLZIKA)}

Correspondencia Alfonso Rodriguez Morales arodriguezm@utp.edu.co

Recibido: 13/03/2016 Aprobado: 13/04/2016

\section{Citar como:}

Rodriguez-Morales AJ, PatiñoValencia S, Villamil-Gómez WE, Alvarado-Socarras JA, JimenezCanizales CE. Situación del Zika en Colombia: experiencia de miembros de la Red Colombiana de Colaboración en Zika (RECOLZIKA). Acta Med Peru. 2016;33(1):79-81
Alfonso J. Rodriguez-Morales ${ }^{1,2}$, Sarita Patiño-Valencia ${ }^{2}$, Wilmer E. VillamilGómez $^{1,3,4}$, Jorge A. Alvarado-Socarras ${ }^{1,5}$, Carlos E. Jimenez-Canizales ${ }^{1,2,6}$

1 Red Colombiana de Colaboración en Zika (RECOLZIKA). Colombia.

2 Grupo de Investigación Salud Pública e Infección, Facultad de Ciencias de la Salud, Universidad Tecnológica de Pereira. Pereira, Risaralda, Colombia.

3 Grupo de Investigación Enfermedades Infecciosas y Control de Infecciones, Hospital Universitario de Sincelejo. Sincelejo, Sucre, Colombia.

4 Programa del Doctorado de Medicina Tropical, Universidad de Cartagena, Cartagena, Universidad del Atlántico. Barranquilla, Colombia.

5 Unidad de Neonatología, Departamento de Pediatría, Fundación Cardiovascular de Colombia, Floridablanca. Santander, Colombia.

6 Secretaría de Salud del Departamento del Tolima, Ibagué. Tolima, Colombia.

\section{Sr. Editor:}

Como es sabido, desde 2014 arribó a Latinoamérica el virus de Zika (ZIKV), afectando inicialmente la Isla de Pascua, Chile [1], donde ya había además circulación de dengue y chikungunya [2], pero posteriormente, Brasil, en 2015, desde donde se expandió rápidamente a múltiples países de América, ya totalizando 31 territorios en la región. Además, con casos importados en Estados Unidos de América, Chile continental, y Perú, donde hasta el 11 de marzo de 2016 el Ministerio de Salud ha confirmado 4 casos.

La infección por ZIKV ocurre en Latinoamérica, en momentos en que aún, el conocimiento sobre este arbovirus es limitado [3]. Su investigación, como ha sido documentado en estudios bibliométricos, ha sido históricamente escasa [3]. Existen muchas dudas sobre su asociación con la microcefalia congénita y con el síndrome de Guillain-Barré [4]. En Colombia, oficialmente los primeros 9 casos llegaron al país procedentes de Brasil, siendo identificados en los municipios de Cartagena y Turbaco (departamento de Bolívar, norte del país). Zona que tiene por demás un alto flujo de turistas internacionales, incluyendo aquellos que proceden de Brasil, entre otros orígenes.

En Colombia se han notificado hasta el 27 de febrero de 2016 (semana epidemiológica número 8), un total de 47771 casos de Zika, de los cuales 2090 son confirmados por laboratorio (RT-PCR), 39 924 casos confirmados por clínica (fiebre, rash, artralgia, conjuntivitis) y 5757 casos sospechosos [5]. Se ha confirmado circulación viral en 282 municipios del territorio nacional (de un total de 1123) y 
Tabla 1. Comparación de la incidencia acumulada de casos en población general y de embarazadas en Colombia, 2015-2016 (hasta 27 de febrero de 2016). Fuente de datos:(5) y DANE (www.dane.gov.co); cálculos propios.

\begin{tabular}{lccc} 
& Población General & Embarazadas & \% Embarazadas \\
Total & $\mathbf{4 7 7 1}$ & $\mathbf{8} 890$ & $\mathbf{1 8 , 6 1}$ \\
Confirmados por laboratorio & 2090 & 812 & 38,85 \\
Confirmados por clínica & 39924 & 7131 & 17,86 \\
Casos sospechosos & 5757 & 947 & 16,45 \\
Población oficial, 2016*,** & 4874632 & 12,12 \\
& & & Razón de Tasas \\
Tasa Incidencia (casos/100 ooo hab.) & 98,00 & 150,41 & 1,53 \\
\hline
\end{tabular}

*Total de la población, proyecciones oficiales del DANE. **Población femenina de 20 a 34,999 años (proyecciones oficiales del DANE).

en 35 de las 37 entidades territoriales mayores (departamentos y distritos). De los municipios $118(41,8 \%)$ corresponden a la región central y $6_{3}(22,3 \%)$ corresponden al caribe (en el norte del país) [5], donde se han además presentado coinfecciones de los tres arbovirus (dengue, chikungunya, Zika) (incluso en el embarazo). Ello obliga a reflexionar y establecer políticas de intervención contundentes contra el vector.

Antioquia es el departamento con mayor número de municipios con casos confirmados por laboratorio (25) [5]. Los departamentos y distritos con mayor casos de Zika (>1000) son: Norte de Santander (8115), Huila (5048), Tolima (4052), Valle del Cauca (3853), Barranquilla (3760), Cundinamarca (3611), Córdoba (2768), Santa Marta (1751), Atlántico (1703), Sucre (1428), Cesar (1147) y San Andrés (1033) [5].

El $67,5 \%$ de los casos de enfermedad por virus Zika se han registrado en mujeres. El 2,7\% de los casos corresponden al grupo de edad de menores de 1 año, 4,48\% en el grupo de 1 a 4 años, $4,15 \%$ de 5 a 9 y $4,41 \%$ de 10 a 14 . El grupo de 25 a 29 años, es el más representado con 14,1\%. La proporción de casos reportada en adultos de 65 años y más es de 3,5\% [5]. Se ha notificado el $0,7 \%$ en pertenencia étnica indígena y el 1,9\% en afrocolombianos.

En relación a las gestantes, del total de casos notificados, $18,61 \%$ (889o) corresponden a ellas, siendo 812 casos confirmados por laboratorio (RT-PCR), 7131 confirmados por clínica y 947 casos sospechosos. Si se estiman tasas de incidencia (casos/100 000 hab.) considerando poblaciones de referencia oficiales, del Departamento Administrativo Nacional de Estadísticas (DANE), para población general y para la de embarazadas, usando como denominador en este caso la población femenina de 20 a 34999 años, se puede apreciar que la tasa de incidencia en embarazadas podría ser 1,53 veces más alta (más aún si se considera que el denominador más real para ellas es menor) (Tabla 1).

En el contexto de todo lo anterior, la respuesta de algunos grupos de investigación en el país, en particular de diez de sus departamentos afectados (Risaralda [Coordinación], Sucre, Tolima, La Guajira, Santander, Caldas, Huila, Cundinamarca, Valle del Cauca y Quindío), hasta el momento, ha sido la creación de la Red Colombiana de Colaboración en Zika (RECOLZIKA). Esta tiene por objetivos analizar el comportamiento epidemiológico de la infección en el país y en los departamentos, así como en Latinoamérica en su contexto, valorar los aspectos clínicos, incluyendo allí la ocurrencia de coinfecciones, formas atípicas y severas (comorbilidades), la asociación con síndrome de Guillain-Barré y la posible asociación con microcefalia y en general su evaluación en el embarazo (cohorte ZIKERNCOL) [6]. RECOLZIKA está trabajando en planificación de estudios que permitan hacer la evaluación entomológica de vectores infectados e incriminados en transmisión en departamentos de la Red. El grupo propone una amplia colaboración con redes internacionales para el desarrollo de proyectos de investigación básica y aplicada, clínica y epidemiológica, con lo cual se han sumado al esfuerzo, colaboradores internacionales que de momento son de Venezuela, Brasil, Estados Unidos de América, México, Honduras, España, Costa Rica, China y Suiza. En ese mismo contexto se pretende generar la cooperación suficiente para el desarrollo de guías de atención basadas en evidencia en el ámbito nacional e internacional, en lo cual ya conjuntamente con la Sociedad Latinoamericana de Medicina delViajero (SLAMVI) y los Comités de Medicina del Viajero de la Asociación Panamericana de Infectología (API) y de la Sociedad Latinoamericana de Infectología Pediátrica (SLIPE) se están desarrollando las "Recomendaciones Temporales Conjuntas para Viajeros y Profesionales de la Salud de la API-CMV, SLAMVI y SLIPE-CMV sobre la infección por virus Zika". 
Las necesidades que plantea la infección por virus Zika son de gran alcance y requieren un abordaje urgente. Se deben llenar muchos vacíos de información científica [3]. Y en tan sentido la cooperación es demandante y necesaria. Los países más afectados deben unir y sumar esfuerzos en la lucha contra una arbovirosis emergente que ha demostrado tener mayor impacto que el esperado inicialmente por la mayoría de las autoridades de salud pública a nivel mundial y regional.

El reto para Colombia es grande, como el segundo país con más casos de Zika. La gran expectativa generada por los casos de microcefalia, necesita un seguimiento muy estrecho especialmente a partir del segundo semestre de 2016. De ahí, que se deban realizar todas las pruebas pertinentes, que permitan confirmar las posibles asociaciones entre Zika y secuelas neurológicas. Adicional a lo anterior, obliga a explorar otros tipos de secuelas, sobre todo en la población infantil.

Fuente de financiamiento: Autofinanciado.

Conflictos de interés: los autores declaran no tener conflictos de interés con la publicación de este artículo.

\section{REFERENCIAS BIBLIOGRÁFICAS}

1. Rodriguez-Morales AJ. Zika: the new arbovirus threat for Latin America. J Infect Dev Ctries. 2015;9(6):684-5.

2. Alfaro-Toloza P, Clovet-Huerta DE, Rodriguez-Morales AJ. Chikungunya, the emerging migratory rheumatism. Lancet Infect Dis. 2015;15(5):510-2.

3. Martinez-Pulgarin DF, Acevedo-Mendoza WF, Cardona-Ospina JA, Rodríguez-Morales AJ, Paniz-Mondolfi AE. A bibliometric analysis of global Zika research. Travel Med Infect Dis. 2016;14(1):55-7.

4. Rodriguez-Morales AJ. Zika and microcephaly in Latin America: An emerging threat for pregnant travelers? Travel Med Infect Dis. $2016 ; 14(1): 5-6$.

5. Instituto Nacional de Salud de Bogotá. Boletín Epidemiológico Semanal, Semana Epidemiológica No. 8, 2016 -Zika [Internet]. Bogotá: INS; 2016 [acceso: 11 de marzo de 2016]. Disponible en: http://www.ins.gov.co/boletin-epidemiologico/Paginas/default. aspx.

6. Villamil-Gómez WE, Mendoza-Guete A, Villalobos E, GonzálezArismendy E, Uribe-García AM, Castellanos JE, et al. Diagnosis, management and follow-up of pregnant women with Zika virus infection: a preliminary report of the ZIKERNCOL cohort study on Sincelejo, Colombia. Travel Med Infect Dis. 2016;14(2):155-8.

\title{
Las ediciones anteriores de Acta Médica Peruana están disponibles en:
}

\author{
www.scielo.org.pe
}

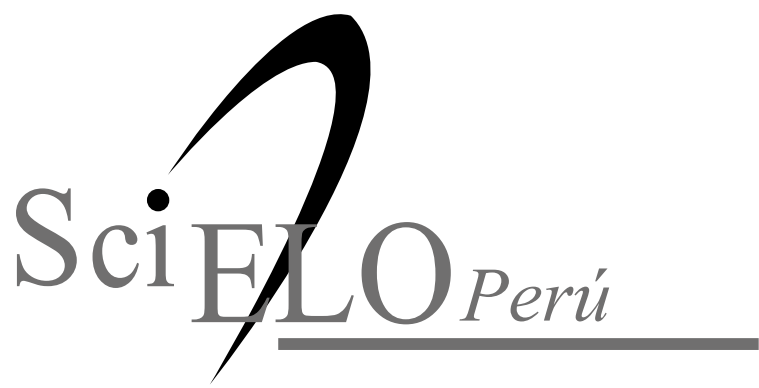

